\title{
What next for gatekeepers?
}

\author{
Sophie Cook clinical editor
}

The BMJ

Part of the burgeoning workload of GPs in the United Kingdom is being an NHS gatekeeper. Successful gatekeeping is a challenge, and poor decisions have consequences. Over-referral risks inappropriate use of resources, while under-referral risks potential harm and dissatisfaction among patients. Direct access to specialists may sound appealing: it could reduce GPs' workload as well as widening patients' access. But what would be the effect on secondary care?

This week Geva Greenfield and colleagues ask whether it's time to rethink primary care's gatekeeper role (doi:10.1136/bmj. i4803). They argue that "a good gatekeeping policy is one that balances clinical needs, patient choice and system restraints." Some commissioning groups have relaxed the rules and offer direct access to specialists for defined groups of patients, but there is wide variation.

Greenfield and colleagues highlight the lack of robust data to support gatekeeping decisions and say that to devise policy we need to know more about the alternatives. Does easier access to specialists mean increased health expenditure? And what are the consequences of strong gatekeeping? They urge a revisiting of gatekeeping policies "to accommodate the government's aim to modernise the NHS," give patients more choice, and promote collaboration between primary and secondary care. But it may be hard to move forward while key questions remain unanswered.
Meanwhile, Margaret McCartney expresses concern that general practice is following the path of dentistry in the UK, which will "do nothing to fix problems in general practice," she says (doi:10.1136/bmj.i4817). GPs cannot see their own patients privately, but they can see another doctor's patient. Increasing opportunities for GPs to take on private work risks disrupting continuity of care, and fewer GPs may be available for people who need urgent care but can't afford private prices. McCartney thinks that GPs who can offer more hours to the NHS should be able to do so. "The independent contractor model, which probably saved the NHS money in its first 70 years, will now strangle it from within," she says.

GPs, specialists, and patients may be relieved by the latest development in the dispute over the junior doctor contract in England, after the series of strikes announced earlier this month were called off. The BMA said it decided to suspend strike action after feedback from doctors, patients, and the public (doi:10.1136/bmj.i5213). Ellen McCourt, newly elected chair of the BMA's Junior Doctors Committee, stands firm in opposing the imposition of the contract and says that the committee now plans "a range of other actions in order to resist it." At the time of going to press it is unclear what these actions may be. Tom Moberly and Abi Rimmer reflect on how the contract dispute has played out so far (doi:10.1136/bmj.i5266). 